ISSN 2179-345X

Licenciado sob uma Licença Creative Commons

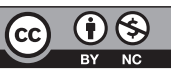

\title{
O papel do Direito para garantir acesso à cultura na sociedade da informação ${ }^{1}$
}

\author{
The role of the Right to ensuring access to culture \\ in the information society
}

\begin{abstract}
Carol Proner ${ }^{[a]}$, Larissa Alcântara Pereira ${ }^{[b]}$
[a] Doutora em Direito, professora de Direitos Humanos do Programa de Mestrado em Direitos Fundamentais e Democracia da UniBrasil, pesquisadora do Núcleo de Pesquisa em Direito Constitucional da UniBrasil (NUPECONST), professora do Programa de Doutorado Derechos Humanos y Desarrollo, Universidade Pablo de Olavide - Espanha, e-mail: carolproner@uol.com.br

${ }^{[b]}$ Advogada, formada pela UniBrasil, Pós-Graduada em Processo Civil pelo Instituto Romeu Felipe Bacellar, pesquisadora do Núcleo de Pesquisa em Direitos Constitucional da Unibrasil (NUPECONST), Mestranda em Direito Constitucional pela UniBrasil, Curitiba, PR - Brasil, e-mail: larissa@kb.adv.br
\end{abstract}

\section{Resumo}

A experiência de quase uma década na aplicação da Lei 9.610/98 vem demonstrando sua insuficiência em atender às demandas de acesso à cultura, o que ficou ainda mais

1 Trabalho apresentado no Simpósio "Sociedade de Informação", realizado nas dependências da PUCPR, no âmbito do Procad/Capes (UFSC, PUCPR, UniBrasil e Unisantos) Sociedade de Informação: democracia, desenvolvimento e inclusão tecnológica. 
evidente com a disseminação da prática de circulação de obras intelectuais em meio digital. A realidade tecnológica evidencia um conflito constitucional atualmente sem solução: a colisão entre a proteção dos interesses do investidor e do criador e o princípio do uso social das propriedades em benefício da coletividade, o que denota a necessidade e importância de se reanalisar o instituto da propriedade intelectual, bem como o papel do Direito na resolução dos conflitos advindos desta realidade, denominada sociedade da informação. Considerando que muitas são as formas de se fomentar a inclusão tecnológica, promovendo o acesso à informação (efetividade do direito à cultura), sendo que nem todas dependerão somente da iniciativa estatal, propõe-se a adoção da política do commons, que consiste no "espírito da dádiva", em que a informação é um bem público e, ao mesmo tempo, insumo do seu próprio processo de produção.

Palavras-chave: Direitos fundamentais. Cultura. Sociedade da informação. Inclusão social. Creative Commons.

\section{Abstract}

The experience on the application of the Law 9.610/98 for almost a decade has demonstrated its insufficiency in responding to the access to culture demands, and this became even clearer through the disseminating practice of circulating intellectual works by digital means. Technological reality shows clearly a constitutional conflict with no solution nowadays: the collision between the protection of the investor's and creator's interests and the principie of the social use of properties for the benefit of the collectivity; this situation demonstrates the need and importance to reanalyze the institute of the intellectual property, as well as the role of the law in the resolution of conflicts coming from this reality called information society. Considering that there are many different ways to promote the technological inclusion, thus promoting the access to information (the effectivity of the right to culture), and once not all of them shall depend uniquely upon the State initiative, the adoption of the commons policy is proposed, which consists in the "spirit of donation", where information is a public good and at the same time an input of its own production process.

Keywords: Fundamental Rights. Culture. Information Society. Social inclusion. Creative Commons. 


\section{A sociedade da informação e o papel do direito}

O nascimento da sociedade da informação, ou da comunicação, foi compreendido por Thomas Kuhn (2003) como a inauguração de um quarto paradigma de revolução científica, rompendo com a racionalidade e a objetividade das ciências do Século das Luzes. Esse conceito, utilizado nos anos 60 e 70, já incorporava a constatação do que ocorria nos primeiros anos do século XX e do que, com uma extraordinária velocidade, prosseguiria em saltos de tecnologia e de conhecimento nos anos seguintes.

A inauguração desse novo paradigma desestruturou todo o conhecimento convencionado pela funcionalidade e objetividade das ciências ditas "puras" presentes no paradigma anterior - racionalidade - e deu origem ao pensamento complexo, à teoria da relatividade, à termodinâmica, à cibernética, à ecologia, aos processos de globalização e a uma quantidade infinita de fenômenos condicionados por essa nova forma de pensar, a partir da "incerteza e das probabilidades", um mundo novo, já anunciado como admirável, e que, como tal, intrinsecamente contraditório.

A contradição dos efeitos não está no potencial de utilização das novas descobertas, mas na forma de utilização, nos objetivos escolhidos pela sociedade a partir de sua correlação de forças. Torna-se inócuo discutir os efeitos das revolucionárias descobertas dos séculos XX e XXI quando não se tem em conta a forma de utilização e distribuição pela sociedade a partir de outras contradições, muitas delas herdeiras de tradições seculares, medievais e que atravessam os tempos intactas, como a divisão da sociedade em classes e a exclusão social.

No campo jurídico, as revoluções desse novo paradigma não foram tão profundas, resistindo ao potencial de transformação que a revolução tecnológica possibilita. O Direito foi, antes, tomado como instrumento capaz de limitar o acesso aos bens e produtos que esse novo mundo apresentava. No caso da propriedade intelectual, o jurídico foi chamado como limite ficcional necessário e sem o qual a exploração da tecnologia, novo fator de produção industrial, não receberia suficiente garantia em 
um ambiente de intensa acumulação do capital a partir da exploração de outros bens, em especial bens de base intangível.

A chamada sociedade da informação está contida na sociedade de acumulação, de concentração de riqueza e de garantias jurídicas próprias demandadas pelo sistema econômico vigente. Não obstante, essa mesma sociedade é subversiva e capaz de produzir outras formas de pensar a partir de outra racionalidade e de valores distintos.

Normalmente, as análises relacionadas com a sociedade da informação descrevem os lados opostos do fenômeno: de um lado, a inovação tecnológica como fator de desintegração social, acentuando a desigualdade social e gerando o acesso restrito à informação; de outro lado, o potencial criativo das inovações tecnológicas como instrumentos de acesso ao conhecimento.

Os dois lados caminham juntos e já não há mais quem insista em criticar os processos comunicacionais como se mundo pudesse ser melhor sem eles. O raciocínio criativo passa a ser aquele que busca nesse universo o potencial do acesso mais amplo e democrático possível, questionando formas de apropriação, ou seja, o tradicional conceito de propriedade, quando estamos diante da produção de bens que não experimentam o fenômeno da escassez.

O jurídico passa a ser chamado para cumprir um papel diferente do que normalmente lhe é demandado nessa matéria. O Direito, como instrumento regulatório dos fluxos de propriedade, também será o marco de limitação da apropriação e da garantia de acesso a bens e ao conhecimento.

Um dos acessos mais reivindicados nesse contexto tem sido o direito à cultura, com reflexos na compreensão de direito de autor e também na concepção mais ampla de propriedade intelectual.

A sociedade da informação tem trazido exemplos reais de experimentação compartilhada da cultura e do conhecimento baseada em critérios que não incluem a apropriação privada. A questão dos commons tem sido discutida nesse marco. O debate está em outra base de diálogo, no entendimento da cultura e da sociedade, das trocas e dos ganhos comuns, 
nas descobertas a partir dos conhecimentos prévios e, principalmente, no caminho para a construção de uma sociedade baseada em critérios de inclusão em oposição ao processo de concentração de saber e riqueza pela regulamentação universal da propriedade intelectual.

Essa nova forma de considerar a propriedade é vista pela indústria cultural como uma subversão da segurança jurídica e das garantias próprias do sistema de direito de propriedade intelectual, sem as quais as obras culturais não poderiam ser protegidas.

Essa oposição de interesses - de um lado, o direito à cultura e ao conhecimento, e de outro, o direito de exploração econômica dos resultados da criação/invenção a partir da proteção jurídica (independente da avaliação da legitimidade social que possa suscitar) - passa a ser uma questão de interesse público, buscando matizações e ponderações que relacionem direitos fundamentais e democracia baseada em critérios de inclusão e de acesso à cultura e ao saber.

\section{Breve histórico da legislação autoral brasileira e ponderação sobre restrição de direitos}

A proteção do direito de propriedade industrial e do direito de autor no Brasil sempre manteve paralelo com os sistemas internacionais de proteção, uniformizando a legislação de acordo com a expectativa internacional manifestada em grandes fóruns, desde as Uniões de Paris e de Berna² até a criação da Organização Mundial da Propriedade

2 A Convenção da União de Paris para a Proteção da Propriedade Intelectual (CUP) foi criada em 20 de março de 1883 e complementada em 1891 por um Protocolo Interpretativo, em Madrid. Um ano mais tarde, em 1884, foi criada a União Internacional para Proteção da Propriedade Industrial, denominada União de Paris, e uma Secretaria Internacional (Bureau da União de Paris) com funções administrativas. A Convenção da União de Berna para Proteção de Obras Artísticas e Literárias (CUB) foi concluída em 9 de setembro de 1886, dando origem à "União de Berna" e a uma Secretaria Internacional (Bureau da União de Berna) com funções administrativas. 
Intelectual $^{3}$ e das novas regras introduzidas pelo Acordo Relativo aos Aspectos da Propriedade Intelectual Relacionados ao Comércio (TRIPS), na Organização Mundial do Comércio (OMC).

O Brasil foi o quarto país na história a legislar sobre patentes, atrás apenas da Inglaterra (1623), dos Estados Unidos (1790) e da França (1791). O Alvará Régio, de 28 de janeiro de 1809, promulgado por ato do príncipe regente D. João VI, estabeleceu o privilégio por catorze anos a inventores ou a introdutores de novas máquinas ou invenções nas artes. A partir de então, o Brasil procurou criar um sistema de incentivo às patentes industriais que substituísse o tradicional sistema de privilégios individuais, culminando em um sistema de patentes que cumpre estritamente com a expectativa de uniformização da propriedade intelectual da OMC.

Quanto ao direito de autor, desde os tempos do Brasil colônia, o País permaneceu por longo período no regime dos privilégios de impressão e de defesa dos direitos autorais (MANSO, 1989, p. 16). A proteção somente foi regulamentada juridicamente em 11 de agosto de 1827, com a Lei de Criação das Faculdades de Direito de Olinda e São Paulo, por meio da qual "os mestres nomeados deveriam encaminhar às Assembléias Gerais os seus compêndios das matérias que lecionavam, a fim de receberem ou não aprovação, com a qual gozariam, também, do privilégio de sua publicação por dez anos" (MANSO, 1989, p. 16).

Com a promulgação do Código Criminal, em 1830, surgiu a primeira regulamentação geral da matéria, embora suas normas se limitassem a proibir a falsificação e a reprodução de obras compostas ou traduzidas por cidadãos brasileiros durante suas vidas, e por mais dez anos após sua morte, caso deixassem herdeiros.

3 A Organização Mundial da Propriedade Intelectual (OMPI/WIPO), criada em 14 de julho de 1967 na Convenção de Estocolmo. Com sede em Genebra, a OMPI adquiriu status de Organismo Especializado da ONU, em 17 de dezembro de 1974. Trata-se de uma organização que goza de capacidade jurídica para concluir acordos bilaterais e multilaterais com Estados-membros, atuando como órgão de apoio às secretarias da União de Berna e da União de Paris. 
Durante o império já se vislumbravam decisões judiciais com o objetivo de consagrar direitos autorais. O primeiro Projeto de Estatuto Civil, realizado por Aprígio Guimarães, professor da Faculdade de Direito do Recife, era composto por oito artigos que garantiam a propriedade intelectual aos autores brasileiros, estendendo-se a proteção post mortem por 30 anos. Esse e outros projetos (entre eles, os de Gavião Peixoto, José de Alencar e Diogo Velho Cavalcante) deram origem à expansão internacional da matéria de direitos autorais no Brasil (ASCENSÃO, 1997, p. 11). Isso porque, já em 1889, o Brasil votou a Convenção de Montevidéu (muito embora não a tenha ratificado), bem como celebrou acordo com Portugal (introduzido no ordenamento pátrio por meio do Decreto n. 10.353), garantindo os direitos intelectuais nacionais aos autores do outro país.

A regulamentação e a garantia dos direitos autorais civis, de forma geral, positiva e com amparo constitucional, deram-se a partir da promulgação da primeira Constituição Republicana, em 1891. Somente a partir dessa data é que a defesa dos direitos autorais passou a fazer parte do cenário jurídico nacional como um direito exclusivo e patrimonial dos autores.

Em 1896, a garantia constitucional prevista no parágrafo 626 do art. 72, foi esmiuçada com a Lei Medeiros de Albuquerque, que teve vigência até o advento do Código Civil, promulgado em janeiro de 1917.

O Código Civil de 1917 regeu a matéria até o ano de 1973, quando surgiu a Lei n. 5.988, instituindo o Conselho Nacional de Direitos Autorais e o Escritório Central de Arrecadação de Direitos Autorais.

No ano de 1998 surge a Lei Autoral n. 9.610, promulgada pelo presidente Fernando Henrique Cardoso, tratando especialmente da matéria e deixando o Código Civil, revisado em 2002, como lei genérica de direito privado. Note-se que, mesmo com a junção das temáticas de direito de autor e de patentes em âmbito internacional, iniciada pela OMPI e seguida pela OMC/TRIPS, em âmbito interno, ambas as categorias de direito receberam tratamento distinto e específico aos respectivos efeitos particulares.

Por força da atual Lei de Direito Autoral, de 1998, a propriedade intelectual pode então ser compreendida como a soma dos direitos 
relativos às obras literárias, artísticas e científicas, interpretações dos artistas intérpretes e execução dos artistas executantes, fonogramas e emissões de radiodifusão, invenções em todos os domínios da atividade humana, descobertas científicas, desenhos e modelos industriais, marcas industriais, comerciais e de serviço, bem como firmas comerciais e denominações comerciais, proteção contra a concorrência desleal e todos os outros direitos inerentes à atividade intelectual nos domínios industrial, científico, literário e artístico (BARBOSA, 2003, p. 1).

O direito de autor recebe consagração constitucional, conforme salienta José de Oliveira Ascensão, no artigo $5^{\circ}$, inciso XXVII da Constituição Federal de 1988, segundo a qual "aos autores pertence o direito exclusivo de utilização, publicação ou reprodução de suas obras, transmissível aos herdeiros pelo tempo que a lei fixar".

O direito de autor é consagrado como direito absoluto, indisponível e hereditário, participando do rol de direitos fundamentais constitucionalmente assegurados, impossibilitando a supressão de tal garantia por lei ordinária e permitindo a exegese constitucional em caso de ponderação de direitos.

No ano de 1986 surge a primeira Lei do Software brasileira (Lei n. 777/86), reformada pela Lei n. 7.646/73, que incorporou, dentre outros dispositivos, normas de proteção ao software nacional de acordo com as exigências de exame de similaridade ao software importado. Na prática, o mecanismo não se mostrou operante, e a nova lei tornou-se objeto de propostas de reforma. O projeto de lei votado e aprovado acabou com o mecanismo de cadastro e avaliação de similaridade, que, ao menos em tese, favorecia a indústria de capital nacional, e conformou à nova lei os interesses do grande capital tecnológico (Lei n. 9.609/98).

Tomando como ponto de análise o acesso à cultura, a atual legislação brasileira tem sido considerada restritiva e desatualizada em relação às necessidades de acesso à cultura e ao conhecimento. $\mathrm{O}$ modelo regulatório autoral deveria garantir aos criadores o legítimo retomo pelo bemestar que propiciam à sociedade, identificando que existem desequilíbrios: 
a diferença de poder econômico entre criadores e investidores; a perda de controle das obras pelos seus próprios criadores; a insatisfação geral com a repartição das receitas e benefícios.

O desafio, em caso de uma atualização na Lei de Direitos Autorais, reside em combinar a legítima proteção aos autores (inclusive no que concerne à melhor remuneração destes) e as inúmeras oportunidades de convergência tecnológicas, que favorecem o sistema nacional de propriedade intelectual moderna, promovendo assim uma sociedade menos desigual no acesso à cultura e ao conhecimento.

Há, portanto, a necessidade de se debater a modernização do sistema legal e o fortalecimento do poder público na supervisão e promoção do equilíbrio principiológico necessário à proteção e à efetividade dos direitos econômicos do autor e do editor, e dos direitos constitucionais e coletivos da sociedade, que é constituída em última instância pelos consumidores das obras intelectuais. Torna-se necessário rediscutir temas como domínio público, limitações e exceções, novas formas de licenciamento, medidas tecnológicas de proteção, gestão coletiva de direitos, modelos de cessão e transferência de direitos patrimoniais, direitos autorais coletivos de grupos étnicos e populações tradicionais.

Para tanto, faz-se necessária a reanálise da propriedade intelectual como um todo, hoje tida como um ramo do Direito que protege as criações intelectuais, facultando aos seus titulares, os quais ditam a forma de comercialização, circulação, utilização e produção dos bens intelectuais ou dos produtos e serviços que incorporam tais criações intelectuais, direitos econômicos.

Importante salientar que o equilíbrio entre os diversos titulares de direito inventor, editor e consumidor não se resolve apenas com modificações pontuais da lei específica; torna-se necessária uma revisão global. Esse é o escopo dos recentes projetos de leis formulados e analisados pelo Ministério da Cultura Brasileiro, que, de forma inovadora, buscam proteger os direitos autorais e obter, com isso, o benefício coletivo que a sua criatividade acarretará para a sociedade como um todo. 


\section{O direito fundamental à cultura e a ponderação constitucional}

No plano do direito internacional, observando a doutrina e a ordem de preocupações para com os direitos humanos, os direitos chamados culturais ocupam o último lugar, ultrapassados pelos direitos civis, políticos, ambientais, sociais e econômicos. A enumeração dos direitos culturais nas declarações internacionais pretere estes em relação aos direitos econômicos e sociais. Mesmo se tratando de mera formalidade, própria da organização sistemática da disciplina, na prática tais direitos efetivamente são preteridos no estudo e na reivindicação de um ideal mais amplo de direitos humanos.

A Declaração de Direitos Humanos de Viena, de 1993, ficou conhecida por introduzir concepção contemporânea que consagrou o princípio da indivisibilidade dos direitos humanos como ideal de realização plena. A indivisibilidade dos direitos humanos costuma ser reivindicada na tradicional separação entre direitos civis e políticos, os chamados direitos de liberdade ou de cidadania, e os direitos sociais e econômicos, entendidos como direitos de igualdade ou direitos materiais. O cultural é visto sempre em menor escala como potencial de interdependência.

As causas de imprecisão incluem a dificuldade de definição dos direitos culturais com efetiva vocação para o cumprimento do conjunto de direitos humanos. A identificação mais comum e imediata os associa a alguma expressão de multiculturalismo: expressão de cultura regional, étnica e religiosa, de identidades e da valorização de localismos, dos costumes e tradições. Outra identificação recorrente os relaciona ao Estado: ao direito à nacionalidade e ao exercício de cidadania, passando pelos direitos dos estrangeiros e dos imigrantes, pelo combate ao racismo e pela luta contra a discriminação.

Mas a real vocação dos direitos culturais está no seu potencial de difusão de conhecimento e de cultura, atuando como ferramenta de aproximação e construção de consensos. O diálogo intercultural, no sentido de aproximação de lugares culturais, tem sido apontado por uma grande quantidade de autores e de teorias das ciências sociais como o caminho para a 
construção de sentidos comuns, o que não significa necessariamente sentidos universais. O diálogo que pressupõe o conhecimento do outro (da cultura, da política, da economia, dos direitos, dos valores) tem sido defendido como potencial para capacitar o entendimento e a busca por soluções comuns, criativas e que podem ser apreendidas por métodos diversos.

Esse papel de distribuição do saber e do conhecimento contrasta radicalmente com uma visão que identifica os direitos culturais como sendo, antes de mais nada, direitos de propriedade cultural, visão que os faz merecer, por parte do direito, ampla e crescente segurança jurídica. A visão dos direitos culturais como direitos de propriedade cultural remonta os tempos de reivindicação da propriedade privada de bens materiais, que, por extensão, alcança a propriedade privada dos bens imateriais. Atualmente, acompanhando a internacionalização das relações comerciais, a proteção da propriedade dos bens culturais passou a ser regulamentada por tratados multilaterais de comércio, submetendo todos os aspectos dos direitos culturais a um indiferenciado regime de apropriação e privatização.

De uma simples leitura da Carta Magna de 1988, é possível vislumbrar que, no âmbito de um Estado Democrático de Direito, essa reflete uma inegável dimensão social, a exemplo do disposto nos artigos $\mathrm{V}, 3^{\circ}$, $6^{\circ}, 7^{\circ}$ e $8^{\circ}$, que dispõem sobre o valor social do trabalho, a igualdade, a solidariedade, entre outros.

Necessária se faz a compreensão do Direito como um instrumento de direção social que permita a implementação e a execução de determinados programas governamentais voltados à promoção da justiça social (FARIA, 2002, p. 19-25), mormente ante a concepção de que a garantia de direitos sociais é justamente um pressuposto para o exercício de outros direitos individuais, especialmente daqueles referentes à participação política. ${ }^{4}$

4 Conforme observação de Robert Alexy a respeito das ideias de Jürgen Habermas, em conferência proferida na Universidade de Externado, Colômbia, publicada na obra Teoria del discurso y derechos humanos, transcrita por Sandro Subtil Silva (2004, p. 124). No mesmo sentido, José Reinaldo de Lima Lopes (2002, p. 113-143). 
De maneira similar, não cabe ao Estado apenas condutas omissivas de respeito aos direitos humanos e fundamentais, mas também um papel ativo de formulação de políticas públicas voltadas para a realização daqueles (SILVA, 1998, p. 198).

Os Fundamentos da República Federativa do Brasil, conforme afirma Fernando Facury Scaff, soberania, cidadania, dignidade da pessoa humana, valores sociais do trabalho e da livre iniciativa, e o pluralismo político, consagrados no artigo $1^{\circ}$ da Constituição de 1988, são os alicerces que toda ação estatal e não estatal deve ter por base (SCAFF, 2006, p. 188189). Um dos meios disponíveis nessa busca dos objetivos é a afirmação e a ampliação dos direitos humanos de segunda dimensão (direitos fundamentais sociais), que são, por definição, direitos a prestações (SCAFF, 2006, p. 189).

Os tradicionais argumentos contrários à aplicabilidade - inexigibilidade intrínseca - dos direitos sociais e culturais residem na não consideração desse grupo de direitos como "direitos" propriamente ditos, alegando que o cumprimento exige, no lugar de uma proibição de lesão (um não fazer), uma obrigação de prestação positiva (um fazer) e que este fazer não seria nem universalizável, nem formalizável e cuja violação não consiste em atos ou comportamentos sancionáveis, mas meras omissões incapazes de coerção. ${ }^{6}$

5 Inobstante a concepção atual seja de unicidade dos direitos fundamentais, por questões metodológicas, ainda se mostra necessária a remissão às dimensões dos direitos fundamentais, tal como apostas por Norberto Bobbio. São elas: a) direitos de primeira geração como direitos individuais civis e políticos, vinculados à liberdade, igualdade, propriedade, segurança e resistência a diversas formas de opressão; portanto, são aqueles inerentes à individualidade, tidos como atributos naturais, inalienáveis e imprescritíveis; b) direitos de segunda geração, compreendidos como os direitos sociais, econômicos e culturais, fundados nos princípios da igualdade e com alcance positivo, ou seja, ensejam sua garantia e concessão a todos os indivíduos por parte do poder público; c) direitos de terceira geração, como os direitos metaindividuais, coletivos (associações) e difusos (genéricos e contingentes), direitos de solidariedade condizentes com a proteção de categorias ou grupos de pessoas; d) direitos de quarta geração, como novos direitos referentes à biotecnologia, bioética e à regulação da engenharia genética; e e) direitos de quinta geração, relativos a novos direitos advindos das tecnologias de informação (internet), do ciberespaço e da realidade virtual em geral (WOLKMER, 2003, Cap. I).

6 Palavras de Luigi Ferrajoli, citando a doutrina conservadora de Friedrich A. von Hayek, Giovani Sartori, Danilo Zolo, dentre outros, no prólogo do livro de Abramovich e Courtis (2003, p. 9). 
Tais direitos, por sua relevância econômica, encontrariam dificuldades na disponibilidade de seu objeto, dependendo da real existência de meios para cumprir a obrigação. Segundo Sarlet (2003, p. 276), “o Estado dispõe apenas de limitada capacidade de dispor sobre o objeto das prestações reconhecidas pelas normas definidoras de direitos fundamentais sociais".

Prevalece, no entanto, a doutrina que supera a divisão estanque em categorias e gerações de direitos e não reconhece diferenças estruturais entre os distintos tipos de direitos. A violação por omissão de um direito econômico, social e cultural poderá ser reparada ainda que tardiamente e terá uma função importante em reafirmar o compromisso do Estado para com esse conjunto de direitos.

O mérito desses juristas imaginativos e criativos, conforme bem afirma Ferrajoli, está em sair das discussões abstratas sobre a estrutura dos direitos sociais e demonstrar com uma numerosa quantidade de casos, extraídos da experiência jurisprudencial dos mais diversos ordenamentos, as estratégias e técnicas que podem fazer possível a exigibilidade desses direitos perante tribunais.

Os direitos econômicos, sociais e culturais são obrigações concretas do Estado, e sobre a exigibilidade recai o trabalho de responsabilização política do Estado para com suas funções fundamentais de administração social. Para garantir direitos civis ou políticos, ao Estado, na maior parte dos casos, também se impõe uma obrigação de "fazer", assim como os Desc também pressupõem obrigações de "não fazer" conexas e complementares.

Os direitos sociais, especificamente o direito à cultura, denota sua importância na medida em que condiz não só com o princípio da dignidade da pessoa, mas também com o princípio democrático, já que privar um ser humano de seu direito a comunicar-se e a receber informações livremente é condená-lo ao empobrecimento intelectual e moral, com reflexo na construção da cidadania. ${ }^{7}$

7 Ver também ESTEBAN, 1998, p. 33. 
Tais direitos, relacionados a prestações positivas a serem prestadas pelo Estado - sem que se esqueça que há ainda a incumbência negativa do Estado, ou seja, do dever de defesa de tais direitos ante os outros direitos subjetivos -, receberam no artigo $6^{\circ}$ da Constituição da República de 1988 o qualificativo de direitos sociais, que impõem severas dúvidas doutrinárias acerca das formas de sua efetivação.

Tem-se, portanto, diante de sua elevada importância e da previsão constitucional que lhe garante, a obrigatoriedade do Estado a atuações positivas, garantindo as condições para que a liberdade e a igualdade do indivíduo e dos grupos em que se integram sejam reais, facilitando a pluralidade dos meios de difusão, bem como o acesso a estes.

A materialização do acesso à cultura dependerá, em muitos casos, do enfrentamento e da ponderação principiológica que ocorre no próprio âmbito constitucional pela proteção simultânea do direito de autor (direito individual) e do direito à cultura (direito coletivo de natureza pública), buscando o equilíbrio justo e que atenda ao interesse público. Nas palavras de Marcos Wachowicz,

a proteção do bem informático na Sociedade Informacional implica a harmonização de conflitos entre o princípio da livre-iniciativa e as restrições à liberdade de concorrência; o princípio da liberdade de informação e as restrições ao acesso e criação de base de dados, e os parâmetros constitucionais de proteção à tecnologia, à autonomia tecnológica e cultura (2007, p. 214).

Especificamente na temática dos direitos autorais e do direito fundamental à cultura, a Constituição Federal de 1988 não só dispõe a tutela dos direitos subjetivos, interesses individuais à produção autoral, como também aponta para a existência de interesses coletivos ou societários no mesmo âmbito temático, cabendo ao Estado o dever de garantir o acesso a tais objetos sociais, consoante disposto nos artigos 215 e 216 (BARBOSA, 2003, p. 135).

Nessa esteira é que o artigo $5^{\circ}$, inciso XXII da $\mathrm{CF} / 88$, que assegura inequivocamente o direito de propriedade, deve ser contrastado com 
as restrições do artigo 170 do mesmo codex, que, ao estabelecer a propriedade privada como princípio essencial da ordem econômica, condiciona-a à função social.

A realidade tecnológica evidencia, portanto, um conflito constituciona $l^{8}$ atualmente sem solução: a colisão entre a proteção dos interesses do investidor e do criador e o princípio do uso social das propriedades em benefício da coletividade (BARBOSA, 2003, p. 98).

Nesse contexto, Marcos Wachowicz (2007, p. 213) alerta que a tensão constitucional em matéria de propriedade intelectual na sociedade informacional, decorrente da efetividade dos direitos fundamentais da informação, da privacidade, da liberdade de iniciativa e da normatização do bem informático pelo direito autoral ou industrial, não pode ser erigida ou interpretada à custa de exclusão ou supressão de direitos fundamentais.

O equilíbrio contrastante dos direitos, levando em conta o interesse constitucional da informação, já foi analisado pelo Tribunal Constitucional da Alemanha e Estados Unidos, sendo que para estes, o conflito se acha moderado pelo princípio de que o direito autoral é uma exclusividade sobre a forma e não sobre o conteúdo da informação (BARBOSA, 2003, p. 101).

O foco, portanto, é promover a inclusão social, a diversidade cultural do País e a língua pátria, por meio do acesso à tecnologia, visando à democratização da informação, conforme redação constante no Decreto 4.901/2003, que institui o Sistema Brasileiro de Televisão Digital. Contudo, para que a inclusão social e a democratização da informação sejam um objetivo atingível nesse processo, é indispensável que a regulamentação de direitos autorais possibilite o exercício pleno de suas limitações e exceções, bem como possibilite o acesso e a livre utilização das obras

8 Nesse passo registre-se que não se trata de um único conflito, vez que outras colisões entre direitos se dão no contexto da inovação tecnológica. A respeito do tema, Manuel Aragón, ao retratar o tema no livro de Maria Luisa Fernandez Esteban, aduz como eventuais outros conflitos "a la libertad de expresión, al derecho de información, al derecho al honor, a la intimidad personal e familiar y a la própria imagen, al derecho a la inviolabilidad del domicilio y al secreto de las comunicaciones, entre otros'” (ESTEBAN, 1998). 
caídas em domínio público ou disponibilizadas pelo autor, por meio de licenças de livre uso como o Creative Commons.

$E$ isto porque o inventor tem o direito de usar, dispor e fruir de seu bem, desde que preservada a sua correspondente função social. Entre as atividades de função predominantemente sociais contempladas pela Constituição Federal de 1988 estão "o pleno exercício dos direitos culturais e acesso às fontes da cultura nacional” - artigo 215.

Neste sentido, o escopo do Ministério da Cultura é estabelecer um equilíbrio entre os criadores e os usuários de obras protegidas por direito de autor, permitindo o acesso, da maneira mais ampla possível, à cultura, mas, ao mesmo tempo, fornecendo elementos que incentivem os criadores. $\mathrm{Ou}$ seja, ao mesmo tempo em que concede direitos exclusivos aos autores, como os de reprodução ou comunicação ao público de suas obras, a Lei imporia algumas limitações e exceções com vistas a permitir que esses direitos não se tornem impeditivos ao acesso à cultura ou ao livre fluxo de ideias dentro da sociedade, tal como já preveem os artigos 46 a 48 da Lei de Direitos Autorais.

Daí a proposta de adoção da Creative Commons ("produção colaborativa”), que evolui para a constituição de uma verdadeira economia das redes de informação baseada na colaboração, tal como adverte Yochai Benkler. Isso porque as redes informacionais não experimentam o fenômeno da escassez, assim, o compartilhamento de um bem não implica perda, pois no mundo digital a informação pode ser partilhada infinitamente (BENKLER, 2007, p. 7).

Busca-se, assim, solver o conflito de direitos por meio de reformas à Lei de Direitos Autorais, de forma a proteger os direitos de propriedade do autor, o dever constitucional da função social da propriedade e o respeito aos direitos coletivos.

\section{Inclusão tecnológica e os commons em busca da efetivação do direito fundamental à cultura}

Muitas são as formas para fomentar a inclusão tecnológica e a maior parte delas passa pelo compromisso do Estado em regulamentar, 
disponibilizar e promover o acesso a esse bem (efetividade do direito à cultura). Mas nem todas dependerão somente da iniciativa estatal para acontecer.

A questão dos commons tem sido discutida nesse marco. Como visto, a ponderação dos commons se faz em outra base de diálogo, tendo como objetivo a construção de uma sociedade baseada em critérios de inclusão em oposição ao processo de concentração de saber e riqueza pela regulamentação universal da propriedade intelectual.

Os commons não são projetos utópicos ou ideias novas; são arranjos que já se manifestam por meio de políticas amplamente difundidas e que produzem resultados extremamente satisfatórios quanto ao cumprimento de seus objetivos gerais e específicos. Os commons, segundo o autor norte-americano Yochai Benkler, são definidos como "um tipo particular de arranjo institucional que governa o uso e a disposição de recurso", tendo como principal característica que

nenhuma pessoa tem o controle exclusivo do uso e da disposição de qualquer recurso particular. Pelo contrário, os recursos governados pela comunidade podem ser utilizados e dispostos por qualquer um entre dado número de pessoas (mais ou menos bem definido) sob regras que podem variar desde o 'vale-tudo' até regras claras formalmente articuladas e efetivamente impostas (BENKLER, 2007, p. 13).

Os commons estão presentes na história da humanidade sempre que a sociedade compartilhou o uso de bens coletivamente e com vantagens para todos. Está intrinsecamente ligado ao bem público. O uso da terra na ausência da apropriação privada, o uso do mar sem restrições territoriais para a navegação e a pesca, o uso das estradas públicas e outros acessos abertos normalmente assegurados pelo Estado, quando representando efetivamente o interesse público, representam uma forma distinta de pensar a propriedade, não significando anarquia ou negação da propriedade, mas atuando nos seus assessórios, no uso e na disposição da propriedade, ampliando ou restringindo a liberdade de acesso. São formas diferenciadas que podem ampliar ou restringir a forma de pensar e usar a propriedade, dependendo das restrições que impõem e a comparação 
feita com a propriedade no sentido tradicional. Os commons podem ser totalmente abertos (de acesso aberto), abertos apenas para um grupo, regulados ou não, ${ }^{9}$ e atualmente têm sido experimentados com grande êxito no campo dos bens e direitos culturais a partir da internet.

A rede mundial de computadores é um exemplo de política de commons instituída por seu próprio inventor. Como nos lembra Sérgio Amadeu da Silveira, "no já longínquo início dos anos de 1990, a criação do Hyper Text Transfer Protocols (HTTP) por Tim Berners-Lee e sua equipe do CERN (Conseil Européen pour la Recherche Nuclátire), laboratório de física de partículas localizado em Genebra, viabilizou o modo gráfico da internet e impulsionou o seu espraiamento". Ao invés de apropriar-se da fantástica invenção, Tim Berners-Lee liberou o http e inspirou a ideia de compartilhamento na rede.

O espírito de compartilhamento, o "espírito da dádiva" parte do propósito segundo o qual a informação é um bem público e, ao mesmo tempo, insumo do seu próprio processo de produção. Nesse sentido, o ambiente digital encontra facilidade para aplicar o espírito da dádiva porque, com velocidade e potencial de difusão, reduz a escassez e amplia a criatividade humana. Segundo Yochai Benkler (2007, p. 275),

a comunicação a baixo custo e os processadores baratos que formam parte integral da produção e da troca da informação criam as condições para colaborações sustentáveis em larga escala e compartilhamento de recursos baseados nos commons, e não nos arranjos institucionais baseados na propriedade.

A rede contém exemplos bem sucedidos de commons, ambientes de produção de informação e cultura livre de restrições (cultura livre), produção descentralizada e aberta, como é o caso dos softwares livres, da Wikipedia, do YouTube, dos projetos como seti@home, como a instituição

9 Um exemplo de commons aberto a todos e sem regulação pode ser entendido como o "ar que se respira", algo possuído e usufruído por todos em compartilhamento, sem necessidade de permissão e sem restrições. O mesmo ar, no entanto, será regulado quanto aos controles de poluição. 
do Creative Commons e do Copy Left, e todas as iniciativas que estabelecem acesso aberto (opens access) e que geram rejeição por parte dos defensores da propriedade intelectual, assustados com as ameaça de um mundo livre.

A política dos commons adotada como valores de partida para o acesso à cultura e ao conhecimento pode trazer um novo enfoque para aproximar os frutos da obra de seus legítimos criadores e estender os benefícios à sociedade. É fato que a ideia já tem sido conectada a valores de liberdade, criatividade, democracia e mais especificamente ao direito do autor (PRONER, 2007c).

\section{Considerações finais}

Os avanços diários da tecnologia, que atingem, de forma maciça, os meios de comunicação, trazem à tona a defasagem da legislação autoral brasileira - que teve sua última alteração há mais de dez anos, deflagrando a urgência de uma nova política nacional para os direitos autorais.

A experiência de quase uma década na aplicação da Lei 9.610/98 vem demonstrando a insuficiência desta em atender as demandas de acesso à cultura, o que ficou ainda mais evidente com a disseminação da pratica de circulação de obras intelectuais em meio digital.

Some-se a isso a necessária inclusão social digital igualitária, como forma de garantia ao direito constitucional à cultura e à informação, legitimando o processo democrático político, na medida em que se garanta a igualdade de acesso informacional aos cidadãos brasileiros.

O desafio então reside em combinar a legítima proteção aos autores com as inúmeras oportunidades de convergência tecnológicas, que favorecem o sistema nacional de propriedade intelectual moderna, promovendo assim uma sociedade menos desigual no acesso à cultura e ao conhecimento.

Mais: o desafio está na necessidade de se debater a modernização do sistema legal e o fortalecimento do poder público na supervisão e 
promoção do equilíbrio principiológico necessário à proteção e efetividade dos direitos econômicos do autor e editor, e dos direitos constitucionais da sociedade, que é constituída em última instância pelos consumidores das obras intelectuais.

Para tanto, faz-se necessária a reanálise do sistema de propriedade intelectual como um todo, entendendo que o equilíbrio entre os titulares de direito (inventor, editor e consumidor) não se resolve apenas com modificações pontuais da lei específica.

Movimentos como o do Creative Commons e novas formas de considerar a propriedade intelectual e o acesso ao conhecimento já estão atuando para construir uma sociedade justa e democrática. O direito e o Estado brasileiro têm o papel de aprender dessa realidade e evitar que novas regulamentações internacionais ou nacionais limitem a inclusão tecnológica de base solidária e compartilhada.

\section{Referências}

ABRAMOVICH, V.; COURTIS, C. Los derechos sociales como derechos exigibles. Madrid: Trotta, 2002.

ABRAMOVICH, V; AÑÓN, M. J.; COURTIS, C. Derechos sociales: instrucciones de uso. México: Doctrina Jurídica Contemporânea, 2003.

ADARRAGA, A. El derecho a la propia imagen. Madrid: Civitas, 1997.

AROCENA, R. et al. Subdesarrollo e innovación: navegando contra el viento. Madrid: Cambridge University Press, 2003.

ASCENSÃO, J. de O. Direito autoral. 2. ed. Rio de Janeiro: Renovar, 1997.

BARBOSA, D. B. Uma introdução à propriedade intelectual. 2. ed. Rio de Janeiro: Lumen Juris, 2003.

BARBOSA, D. B. Propriedade e quase-propriedade no comércio de tecnologia. Brasília: CNPq, 1981. 
BARBOSA, D. B. The tax treatment of software in US and foreign law. Columbia: Columbia University, 1983.

BASSO, M. 0 direito internacional da propriedade intelectual. Porto Alegre: Livraria do Advogado, 2000.

BENKLER, Y. Comunicação digital e construção dos commons: redes virais, espectro aberto e as novas possibilidades de regulação. São Paulo: Fundação Perseu Abramo, 2007.

BERCOVITZ, R. Manual de propriedade intelectual. 3. ed. Valencia: Tirant lo blanch, 2006.

BRUGUIÉRE, M. et al. Droit d'auteur et culture. Paris: Éditions Dalloz, 2007.

CABRAL, P. Direito autoral: dúvidas e controvérsias. São Paulo: Harbra, 2000.

CARVAlHO, P. L. de. Propriedade intelectual. Curitiba: Juruá, 2005.

CARVALHO, H. de. Sementes: patrimônio do povo a serviço da humanidade. São Paulo: Expressão popular, 2003,

CHAVES, A. Direitos autorais na computação de dados. São Paulo: LTr, 1996. CLÈVE, C. M. et al. (Coord.). Direitos humanos e democracia. Rio de Janeiro: Forense, 2007.

CORIAT, B.; CORTI, F. Derechos de propriedad intelectual e innovación. Documento para el seminário Propriedad Intelectual e innovación, Buenos Aires, 3 al 6 de diciembre, 2007.

DIREITO, C. A. M. A disciplina constitucional da propriedade industrial. Revista de Direito Administrativo, n. 185, p. 19-25, jul./set. 1991.

ESPÍNOLA, E. Posse, propriedade, compropriedade ou condomínio no direito autoral. Campinas: Bookseller, 2002.

ESTEBAN, M. L. F. Nuevas tecnologias, internet y derechos fundamentales. Madrid: McGraw-Hill, 1998. 
FACHIN, L. E. Da propriedade como conceito jurídico. Revista dos Tribunais, v. 76 , n. 621, p. 16-39, jul. 1987.

FARIA, J. E. Judiciário e desenvolvimento econômico. In: FARIA, J. E. (Org.). Direitos humanos, direitos sociais e justiça. São Paulo: Malheiros, 2002. p. 11-29.

GALDELMAN, H. O que você precisa saber sobre direitos autorais. Rio de Janeiro: Senac Nacional, 2004.

GLATIN, M. Le. Internet: um séisme dans la culture? Toulouse: Éditions de l'attribut, 2007.

GNOCCHI, A. A propriedade intelectual e o ideal pan-americano. São Paulo: Internacional Propriedade Intelectual, 1961.

HAMMES, B. J. Origem e evolução histórica do direito de propriedade intelectual. Estudos Jurídicos, v. 24, n. 62, p. 105-115, set./dez. 1991.

HERMAN, E. S. et al. Los medios globales: los nuevos misioneros del capitalismo comorativo. Madrid: Catedra, 1999.

JOELLE, F. Internet et le droit d'auteur. Paris: CNRS Editions, 2003.

KLEIN, N. Sem logo: a tirania das marcas em um planeta vendido. Rio de Janeiro: Record, 2002.

KUHN, T. A estrutura das revoluções científicas. 7. ed. São Paulo: Perspectiva, 2003.

LOPES, J. R. de L. Direitos subjetivos e direitos sociais. In: FARIA, J. E. (Org.). Direitos humanos, direitos sociais e justiça. São Paulo: Malheiros, 2002. p. 113-143.

MORO, M. C. Direito de marcas. São Paulo: Revista dos Tribunais, 2003.

PAES, P. R. T. Propriedade industrial. 2. ed. Rio de Janeiro: Forense, 2000.

PRONER, C. Propriedade intelectual: para uma outra ordem jurídica possível. São Paulo: Cortez, 2007a. 
PRONER, C. Propriedade intelectual e direitos humanos: sistema Internacional de Patentes e Direito ao Desenvolvimento. Porto Alegre: Sergio Antonio Fabris, 2007b.

PRONER, C. Quais os limites a Propriedade Intelectual. Carta Maior, 5 nov. 2007c. Entrevista concedida a Marco Aurélio Weissheimer.

RUBIO, D. S. et al. Nuevos colonialismos del capital: propriedade intelectual, biodiversidade e direitos dos povos. Barcelona: Icaria Editorial, 2004.

SARLET, I. W. A eficácia dos direitos fundamentais. Porto Alegre: Livraria do Advogado, 2003.

SCAFF, F. F. Como a sociedade financia o estado para a implementação dos direitos humanos no Brasil. São Paulo: Notadez, 2006. p. 188-189.

SHERWOOD, R. Propriedade intelectual e desenvolvimento econômico. São Paulo: EDUSP, 1992.

SILVA, C. G.; MELLO, L. C. P. (Coord.). Ciência, tecnologia e inovação: desafios para a sociedade brasileira. Brasília: Ministério da Ciência e Tecnologia. Academia Brasileira de Ciências, 2001.

SILVA, J. M. da. A consideração da dignidade humana como critério de formulação de políticas públicas. In: PUSSOLI, M. L. M. L. (Coord.). Cultura dos direitos humanos. São Paulo: Ltr, 1998. p. 194-198.

SILVA, L. G. et al. Direito da propriedade intelectual. Curitiba: Juruá, 2006.

SILVA, S. S. Surgimento e evolução do Estado Social. Revista da ProcuradoriaGeral do Estado/ Procuradoria-Geral do Estado do Rio Grande do Sul, v. 28, n. 60, p. 115-128, jul./dez. 2004.

SILVEIRA, S. A. da et al. Comunicação digital e a construção dos commons. São Paulo: Fundação Perseu Abramo, 2007.

STRENGER, I. Marcas e patentes. São Paulo: Forense Universitária, 1996.

TACHINARDI, M. H. A guerra das patentes. São Paulo: Paz e Terra, 1993. 
TELLINI, D. E. Regime de Direito internacional privado na responsabilidade dos provedores de internet. Porto Alegre: Sergio Antonio Fabris, 2006. VIDE, C. R. (Coord.). Los limites de derecho de autor. Madrid: Reis, 2006. VIVANT, M. (Dir.). Proprieté intellectuelle et mondialisation: la proprieté intellectuelle est-elle une marchandise. Paris: Dalloz, 2004.

WACHOWICZ, M. (Coord.). Propriedade intelectual e internet: uma perspectiva integrada à Sociedade da Informação. Curitiba: Juruá, 2005.

WACHOWICZ, M. (Coord.). Propriedade intelectual do software e revolução da tecnologia da informação. Curitiba: Juruá, 2007.

WOLKMER, A. C. Os novos direitos no Brasil: natureza e perspectivas: uma visão básica das novas conflituosidades jurídicas. São Paulo: Saraiva, 2003. Cap. I.

Recebido: 16/11/2009

Received: 11/16/2009

Aprovado: 23/02/2010

Approved: 02/23/2010 